\title{
Clinical Outcomes of a Redo for a Failed Colorectal or Coloanal Anastomosis
}

\author{
In Teak Woo, Jun Seok Park, Gyu-Seog Choi, Soo Yeun Park, Hye Jin Kim, In Kyu Park \\ Colorectal Cancer Center, Kyungpook National University Medical Center, School of Medicine, Kyungpook National University, Daegu, Korea
}

Purpose: Redo surgery in patients with a persistent anastomotic failure (PAF) is a rare procedure, and data about this procedure are lacking. This study aimed to evaluate the surgical outcomes of redo surgery in such patients.

Methods: Patients who underwent a redo anastomosis for PAF from January 2004 to November 2016 were retrospectively evaluated. Data from a prospective colorectal database were analyzed. Success was defined as the combined absence of any anastomosis-related complications and a stoma at the last follow-up.

Results: A total of 1,964 patients who underwent curative surgery for rectal cancer during this study period were included. Among them, 32 consecutive patients underwent a redo anastomosis for PAF. Thirteen patients of those 32 had major anastomotic dehiscence with a pelvic sinus, 12 had a recto-vaginal fistula, and 7 had anastomosis stenosis. There were no postoperative deaths. The median operation time was 255 minutes (range, $80-480$ minutes), and the median blood loss was $80 \mathrm{~mL}$ (range, $30-1,000 \mathrm{~mL}$ ). The overall success rate was $78.1 \%$, and the morbidity rate was $40.6 \%$. Multivariable analyses showed that the primary tumor height at the lower level was the only statistically significant risk factor for redo surgery $(\mathrm{P}=0.042$; hazard ratio, 2.444).

Conclusion: In our experience, a redo anastomosis is a feasible surgical option that allows closure of a stoma in nearly $80 \%$ of patients. Lower tumor height $(<5 \mathrm{~cm}$ from the anal verge) is the only independent risk factor for nonclosure of defunctioning stomas after primary rectal surgery.

Keywords: Redo surgery; Rectal cancer; Persistent anastomotic failure; Laparoscopy

\section{INTRODUCTION}

After colorectal anastomosis or coloanal anastomosis, the postoperative course can be complicated by persistent anastomotic failure (PAF). Such a complication can be responsible for multiple consequences, such as chronic strictures, urinary or vaginal fistulae, and persisting presacral sinuses [1]. Chronic anastomotic strictures and presacral sinuses are observed in $3 \%-30 \%$ of pa-

Received: December 7, 2017 - Accepted: May 4, 2018

Correspondence to: Jun Seok Park, M.D.

Colorectal Cancer Center, Kyungpook National University Medical Center,

807 Hoguk-ro, Buk-gu, Daegu 41404, Korea

Tel: +82-53-200-2166, Fax: +82-53-200-2027

E-mail: parkjs0802@mail.knu.ac.kr

ORCID code: https://orcid.org/0000-0001-5443-6748

(C) 2018 The Korean Society of Coloproctology

This is an open-access article distributed under the terms of the Creative Commons Attribution NonCommercial License (http://creativecommons.org/licenses/by-nc/4.0) which permits unrestricted noncommercial use, distribution, and reproduction in any medium, provided the original work is properly cited. tients, depending on the definition adopted, and most of these lead to poor anastomotic function, frequent bowel movements, and sometimes pelvic sepsis [2-5]. In addition, $0.5 \%$ to $3 \%$ of patients with low rectal anastomosis develop recto-vaginal fistulae (RVFs) or urethral fistulae, resulting in extremely uncomfortable symptoms [6, 7]. Various local treatment options, from a "waitand-see" approach with proximal diversion to flap formation via a transanal or transvaginal, may be considered. However, the success rates of these conservative approaches are not promising, and many patients with PAF remain with a permanent stoma [8-11].

For patients with permanent stomas, despite the intraoperative technical difficulties, redo surgery with a new coloanal or colorectal anastomosis may represent the last valuable option after all local repair procedures have been attempted. As very few studies on this subject have been reported to date, little is known about the risk factors and clinical outcomes of redo surgery. Thus, this study aimed to report our experiences with a redo anastomosis as a treatment option for patients experiencing PAF. 


\section{METHODS}

\section{Patients}

All patients who underwent a redo anastomosis for PAF between January 2004 and November 2016 were identified from the prospective database of the Colorectal Department at Kyungpook National University Medical Center. Demographics, disease features (etiologies of PAF, durations of disease, and previous interventions), redo surgical procedure-related variables, perioperative morbidity, mortality, and follow-up data were documented. This study was approved by the Institutional Review Board of the Kyungpook National University Medical Center. All patients gave their informed consent in writing prior to surgery during the study period.

\section{Surgical technique}

All primary and redo surgeries were conducted by 4 surgeons. All enrolled patients underwent a curative resection for primary colorectal cancer. There was no definitive contraindication for redo surgery. Generally, if pelvic recurrence was suspected preoperatively, a redo anastomosis was not recommended to the patients. Since 2007, we have gradually increased the application of a laparoscopic system in the treatment of patients with PAF. The same surgical principles and steps were applied in both laparoscopic and open procedures. Open surgery was performed in patients who were expected to have severe adhesion from a previous operation or in those who were expected to have incomplete anastomosis with laparoscopic surgery.

Because the causes of PAF were not the same, the necessary operative techniques had to be adjusted according to the anastomotic pathology. Surgery was performed in the lithotomy position via a midline incision or multiport laparoscopic approach. An adhesiolysis was conducted initially. In most patients, splenic flexure was completely taken down, and the left colon was fully mobilized with the aim of having a tension-free, well-vascularized proximal colonic stump. If the left colon was not available, the inverted right colon was brought down to the pelvis (Deloyers procedure) [12]. All proctectomies were performed through an open or a laparoscopic approach, and the distal stump was identified by following the colon. The methods of reconstruction, such as hand-sewn coloanal anastomosis or straight anastomosis with double stapling technique, depended on the local pelvic condition and previous surgical history. When redo surgery was performed for stricture, the colon was usually transected at least $1-2 \mathrm{~cm}$ above the stenosis. When sclerosis of the distal rectal stump was not severe, circular staplers were used caudally for an end-to-end anastomosis. When the conditions of the rectal stump were unfavorable, the distal stump was resected, and reconstruction was performed with a hand-sewn straight coloanal anastomosis. In case of an RVF, an attempt was made to identify the fistulous orifice after the primary proctectomy and to close it via transvaginal access.

\section{Definition}

The main endpoint of the study was the successful restoration of digestive continuity with particular focus on postoperative morbidity. PAF was defined as an anastomotic failure or chronic pelvic sepsis for more than 6 months postoperatively. Success was defined as the combined absence of any anastomosis-related complications and a stoma at the last follow-up. Mortality was defined as death occurring in the hospital or within 90 days postoperatively. Postoperative morbidity was stratified according to the Clavien-Dindo classification [13].

\section{Statistical analysis}

The compared variables included patients' index characteristics. The normal distribution of the collected data was first evaluated using the Kolmogorov-Smirnov test. Normally distributed data were analyzed using a parametric test, and the result was expressed as mean \pm standard deviation; data that were not normally distributed were analyzed using a nonparametric test, and the result was expressed as median value with range. All variables considered clinically significant underwent a multivariate analysis using the Cox proportional-hazard regression model. A P-value of $<0.05$ was taken as being statistically significant. Statistical analyses were performed using IBM SPSS Statistics ver. 20.0 (IBM Co., Armonk, NY, USA).

\section{RESULTS}

During the study period, 32 consecutive patients underwent a redo anastomosis for PAF and were included in the study. As shown in Fig. 1, the 3 main causes for redo surgery were anastomotic dehiscence with chronic pelvic sepsis, an RVF, or an anastomotic stricture intractable to local treatment. Among the 174 patients with a failed anastomosis, 142 patients were successfully treated with conservative care, and 32 patients required redo surgery. The details of the 142 patients who were successfully treated with conservative care are as follows: 82 patients were treated with an ileostomy or colostomy, 36 with non-per oral diet and antibiotics therapy, 14 with transanal primary suture, and 10 with percutaneous drainage.

Thirty-two patients underwent redo surgery for persistent anastomosis failure. Among them, 28 underwent an ileostomy, 3 a colostomy, and 1 a Hartmann procedure. The characteristics of these 32 patients are shown in Table 1 . The median age at the time of redo surgery was 53 years (43-83 years), and 1 patients $(3.1 \%)$ had an American Society of Anesthesiologists (ASA) physical status classification of III to IV. Among the 32 patients, the inferior mesenteric artery was preserved in 1 patient during the initial operation. However, when we analyzed all patients who underwent a low anterior resection, no significant differences in the overall PAF rates were found between the high-tie group (154 of 1,809, $8.5 \%)$ and the low-ligation group $(20$ of $155,12.9 \%)(\mathrm{P}=0.065)$. In the initial operation, a primary anastomosis was created with a 


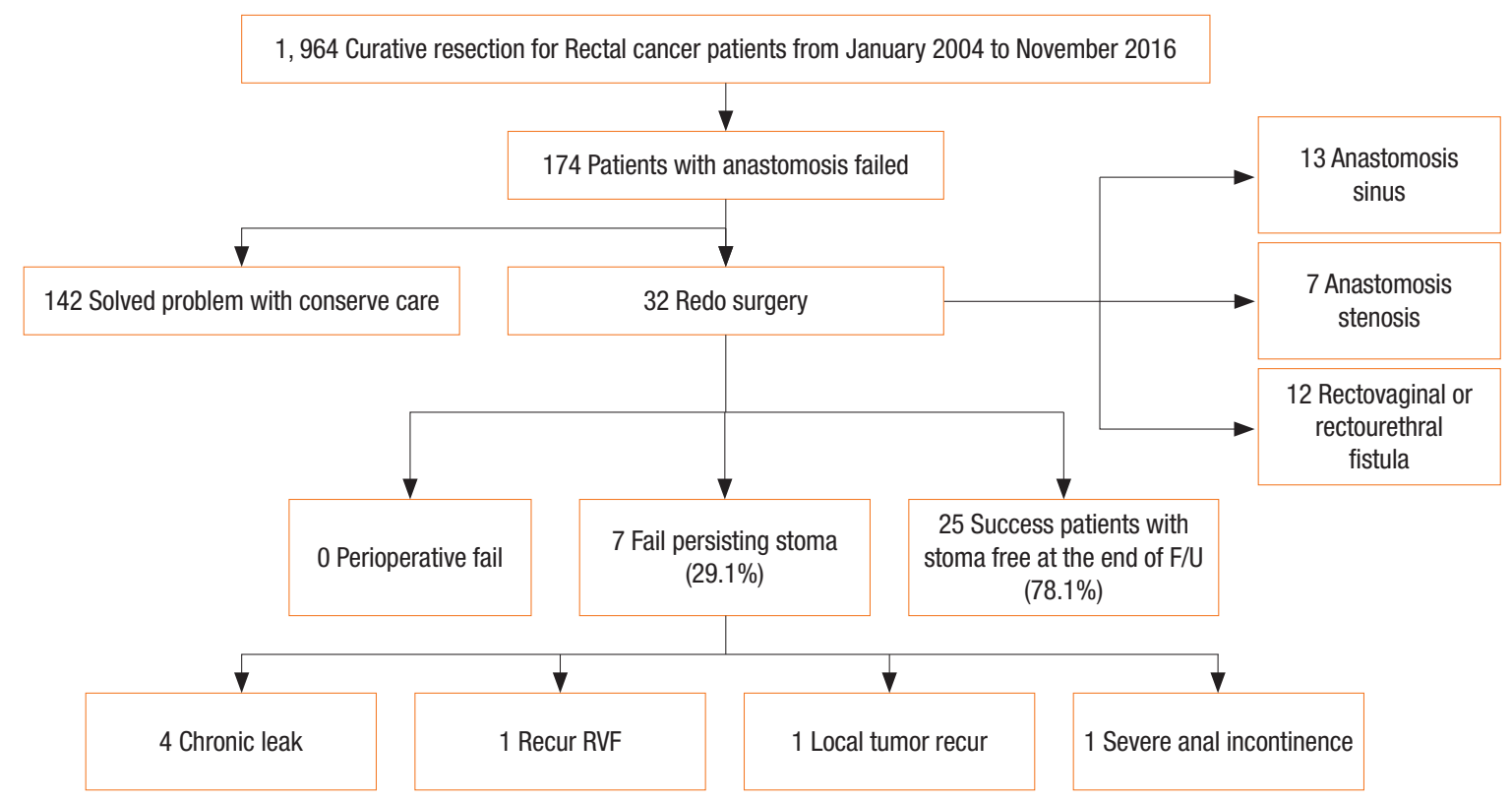

Fig. 1. Flowchart to obtain the results of a curative resection for rectal cancer patients. F/U, follow-up; RVF, recto vaginal fistula.

Table 1. Characteristics of the patients who underwent redo surgery ( $\mathrm{n}=32$ )

\begin{tabular}{|c|c|}
\hline Characteristic & Value \\
\hline Age (yr) & $60.6 \pm 10.6$ \\
\hline Sex, male : female (\%) & $19(59.3): 13(40.7)$ \\
\hline Body mass index $\left(\mathrm{kg} / \mathrm{m}^{2}\right)$ & $23.4 \pm 3.1$ \\
\hline Tumor distance from AV (cm) & $5.5(1-12)$ \\
\hline Anastomosis level of AV (cm) & $3(0-8)$ \\
\hline \multicolumn{2}{|l|}{ ASA PS classification (\%) } \\
\hline I & $15(46.8)$ \\
\hline$\|$ & $16(50.0)$ \\
\hline III & $1(3.1)$ \\
\hline Diabetes mellitus & $2(6.3)$ \\
\hline Interval from primary surgery to redo surgery (mo) & $7.3(6-126.7)$ \\
\hline \multicolumn{2}{|l|}{ IMA tie $(\%)$} \\
\hline High tie & $31(96.9)$ \\
\hline Low tie & $1(3.1)$ \\
\hline Preoperative CCRT & $17(53.1)$ \\
\hline \multicolumn{2}{|l|}{ Type of primary anastomosis } \\
\hline Stapled colorectal anastomosis & $17(53.1)$ \\
\hline Stapled coloanal anastomosis & $4(12.5)$ \\
\hline Hand-sewn coloanal anastomosis & $11(34.3)$ \\
\hline \multicolumn{2}{|c|}{$\begin{array}{l}\text { Values are presented as mean } \pm \text { standard deviation, number (\%), or median (in } \\
\text { terquartile range). } \\
\text { AV, anal verge; ASA PS, American Society of Anesthesiologists physical status } \\
\text { IMA, inferior mesenteric artery; CCRT, combined chemotherapy and radiation } \\
\text { therapy. }\end{array}$} \\
\hline
\end{tabular}

median height of $3 \mathrm{~cm}(0-8 \mathrm{~cm})$ from the anal verge. Before redo surgery, nine patients with pelvic sepsis due to an anastomotic failure underwent general surgery (stoma creation and abdominal lavage), and 7 patients with an RVF underwent transvaginal or transanal primary repair. Among the four patients with a benign anastomosis stenosis, one patient underwent endoscopic dilatation before redo surgery, and 3 underwent transanal dilation with a bougie, with a median of 2 (1-4) dilatations per patients.

Details of the preoperative and the postoperative results are shown in Table 2 . Redo surgery was technically feasible, and restoration of bowel continuity was achieved in all 32 patients. The median length of hospital stay was 13 days (5-44 days). A total of 22 patients had a defunctioning stoma, which included the 17 patients who had already had a stoma before redo surgery. Intraoperative complications were observed in 3 patients (11\%), mainly represented by ureter injury due to multiple adhesions and difficult pelvic dissection. Perioperative transfusion was required in 1 patient $(0.3 \%)$ for a pelvic hemorrhage related to a presacral venous plexus injury. There were no immediate postoperative mortalities. During the immediate postoperative period, 5 patients had severe postoperative complications (Clavien-Dindo grade $>$ III). Among them, 4 patients suffered major anastomotic leakage requiring surgery with general anesthesia (secondary redo anastomosis $[\mathrm{n}=3$ ]; abdominal lavage with ileostomy creation [ $\mathrm{n}=$ 1]). The other patient had a presacral abscess requiring percutaneous drainage. We performed redo surgery more frequently through the laparoscopic approach $(n=19,59.3 \%)$ than through the open approach $(n=13,40.7 \%)$. For redo surgery, no difference in morbidity was found between the laparoscopic $(n=6$, $31.6 \%)$ and the open $(n=6,46.2 \%)$ groups $(P=0.403)$. The hos- 


\section{Coloproctology}

pital stay of the laparoscopic redo surgery group, 12 days (range, 6-36 days), was shorter than that of the open redo surgery group, 19 days (range, $9-195$ days) $(\mathrm{P}=0.008)$. Moreover, wound complication occurred less frequently in the laparoscopic group $(\mathrm{n}=0$, $0 \%)$ than in the open group $(\mathrm{n}=3,23.1 \%)(\mathrm{P}=0.028)$. With a median follow-up of 30.3 months (range, 5-137 months), the

Table 2. Pre- and postoperative details of the patients who underwent redo surgery $(\mathrm{n}=32)$

\begin{tabular}{lc}
\hline Variable & Value \\
\hline Redo surgery & \\
\hline Laparoscopic approach : open approach & $19(59.3): 13(40.7)$ \\
Ileostomy at redo surgery & $22(68.7)$ \\
Operation time (min) & $223.4 \pm 81$ \\
Blood loss (mL) & $81.7 \pm 380$ \\
Postoperative hospital stay (day) & $14(6-195)$ \\
Complication $^{\text {a }}$ & $13(40.6)$ \\
\hline Clavien-Dindo classification I/II & $8(25.0)$ \\
\hline Small bowel obstruction & 3 \\
\hline Wound complication & 3 \\
\hline Voiding difficulty/UTI & 2 \\
\hline Clavien-Dindo classification III & $5(15.6)$ \\
$\quad$ Leakage & 4 \\
\hline Presacral abscess & 1 \\
\hline Long-term success & \\
\hline Success without reintervention & $23(71.8)$ \\
\hline Success with reintervention & $2(6.2)$ \\
Failure with persisting stoma & $7(21.8)$ \\
Mortality ${ }^{a}$ & $0(0)$ \\
\hline
\end{tabular}

Values are presented as number (\%), mean \pm standard deviation, or median (interquartile range).

UTI, urinary tract infection.

${ }^{a}$ Complication \& mortality are postoperative within 90 days. overall success rate was $78.1 \%(n=25)$. At the end of follow-up, seven patients did not have stoma closure (persistent anastomotic dehiscence with pelvic sepsis $[\mathrm{n}=5]$, declined intervention $[\mathrm{n}=$ $1]$, and recurred RVFs [ $n=1]$ ).

This study involved 4 experienced surgeons. One was a highvolume surgeon (HVS) who had performed more than 100 surgeries on patients with rectal cancer per year. The other 3 surgeons were low-volume surgeons (LVSs) who had performed fewer than 50 surgeries on patients with rectal cancer per year. However, no statistically significant difference in the success rate of the redo operation was found between the HVS and the LVSs. ( 5 of 22 [77.3\%] vs. 2 of 10 [80.0\%], P = 0.863). Table 3 shows the detailed characteristics of patients with failed redo surgery. Five patients developed anastomosis leakage after redo surgery. All of them showed overall failure and had a permanent stoma until the last follow-up.

The results of multivariable analyses of risk variables for redo surgery are presented in Table 4 . Sex, age, body mass index, inferior mesenteric artery tie level, diabetes mellitus, preoperative continuous renal replacement therapy, and clinical $\mathrm{T}$ stage were factors not related to redo surgery. However, primary tumor height was the only statistically significant risk factor for redo surgery $(\mathrm{P}=0.042$; hazard ratio, 2.444$)$. When the primary tumor heights of all patients were analyzed, those with redo surgery were found to have lower tumor height than the other patients (5.5 [1$12] \mathrm{cm}$ vs. $7.0[0-12] \mathrm{cm})(\mathrm{P}=0.008)$. Among the 12 female patients with RVFs, 9 underwent double-stapling anastomosis, which was more frequently used than the hand-sewn technique ( $75 \%$ vs. $25 \%$ ). In addition, our analysis showed that the doublestapling technique tended to be associated with a higher risk of redo surgery than the hand-sewn technique, but that difference did not reach statistical significance $(\mathrm{P}=0.108)$.

\section{DISCUSSION}

Sphincter-preserving surgery in the management of rectal pathol-

Table 3. Details for the 7 patients who failed redo surgery

\begin{tabular}{|c|c|c|c|c|c|c|c|c|c|c|c|c|c|}
\hline Patients & Sex & $\begin{array}{l}\text { Age } \\
(y r)\end{array}$ & $\begin{array}{c}\text { BMl } \\
\left(\mathrm{kg} / \mathrm{m}^{2}\right)\end{array}$ & ASA & $\begin{array}{c}\text { Tumor } \\
\text { height } \\
(\mathrm{cm})\end{array}$ & $\begin{array}{l}\text { Pre- } \\
\text { CCRT }\end{array}$ & $\begin{array}{c}\text { cT } \\
\text { stage }\end{array}$ & $\begin{array}{l}\text { Reason } \\
\text { for redo }\end{array}$ & $\begin{array}{l}\text { Procedure before } \\
\text { redo surgery }\end{array}$ & Tool & $\begin{array}{l}\text { OP time } \\
\text { (min) }\end{array}$ & $\begin{array}{c}\text { Hospital } \\
\text { stay } \\
\text { (day) }\end{array}$ & Morbidity \\
\hline 1 & $\mathrm{M}$ & 68 & 16 & $\|$ & 5 & Yes & III & Sinus & Drain & Lapa & 120 & 7 & Sinus \\
\hline 2 & $\mathrm{M}$ & 79 & 18 & $\|$ & 7 & No & I & Sinus & Repair & Open & 380 & 56 & Sinus \\
\hline 3 & M & 43 & 23 & I & 3 & Yes & IV & Steno & No & Lapa & 240 & 6 & Sinus \\
\hline 4 & M & 55 & 23 & III & 3 & Yes & $\|$ & Steno & Redo surgery & Open & 120 & 122 & Sinus \\
\hline 5 & $\mathrm{~F}$ & 74 & 24 & $\|$ & 5 & No & III & Fistula & No & Lapa & 300 & 10 & Rectovaginal fistula \\
\hline 6 & M & 52 & 25 & $\|$ & 7 & Yes & III & Sinus & No & Open & 250 & 30 & Pelvic area tumor recurrence \\
\hline 7 & $\mathrm{~F}$ & 83 & 23 & । & 5 & Yes & |l| & Fistula & Repair & Lapa & 180 & 17 & Incontinence \\
\hline
\end{tabular}

BMI, body mass index; AV, anal verge; ASA, American Society of Anesthesiologists physical status classification; IMA, inferior mesenteric artery; CCRT, combined chemotherapy and radiation therapy; cT stage, clinical T stage; OP, operation; Lapa, laparoscopy. 
Table 4. Results of univariate and multivariate analyses using Cox proportional-hazard regression for risk variables of persistent anastomotic failure requiring a redo anastomosis

\begin{tabular}{lccccc}
\hline \multirow{2}{*}{ Variable } & \multicolumn{2}{c}{ Univariate } & & \multicolumn{2}{c}{ Multivariate } \\
\cline { 2 - 3 } \cline { 5 - 6 } \cline { 5 - 6 } Sex & HR & P-value & & HR $(95 \% \mathrm{Cl})$ & P-value \\
\hline Female & 1 & - & $0.875(0.416-1.840)$ & 0.725 \\
$\quad$ Male & 1.238 & 0.569 & 1 & - \\
Age (yr) & & & & & \\
$<70$ & 1 & - & & $1.620(0.663-3.960)$ & 0.290 \\
$\geq 70$ & 0.529 & 0.155 & 1 & -
\end{tabular}

Body mass index $\left(\mathrm{kg} / \mathrm{m}^{2}\right)$

$\begin{array}{cccc}<27.5 & 1 & - & - \\ \geq 27.5 & 0.891 & 0.850 & 0.841\end{array}$

Tumor height (cm)

$\begin{array}{ccccc}<5 & 1 & - & 2.444(1.033-5.783) & 0.042 \\ \geq 5 & 0.622 & 0.227 & 1 & -\end{array}$

Surgical approach

$\begin{array}{lcccc}\text { Low tie } & 1 & - & 0.448(0.059-3.419) & 0.439 \\ \text { High tie } & 2.685 & 0.313 & 1 & - \\ \text { Preoperative CCRT } & & & & \end{array}$

\begin{tabular}{lcccc} 
No & 1 & - & $0.515(0.192-1.382)$ & 0.188 \\
Yes & 2.121 & 0.145 & 1 & - \\
Anastomosis fashion & & & & \\
$\quad$ Hand-sewn & 1 & - & $0.503(0.218-1.162)$ & 0.108 \\
$\quad$ Stapled & 1.159 & 0.693 & 1 & - \\
Diabetes mellitus & & & & \\
No & 1 & - & $0.631(0.147-2.710)$ & 0.536 \\
Yes & 1.485 & 0.590 & 1 & - \\
Clinical T-stage & & & & \\
T1-2 & 1 & - & $0.874(0.416-1.836)$ & 0.722 \\
T3-4 & 1.092 & 0.814 & 1 & - \\
\hline
\end{tabular}

CCRT, combined chemotherapy and radiation therapy; HR, hazard ratio; Cl, confidence interval.

ogy is increasingly being performed with recent efforts to avoid definitive stomas. However, anastomotic insufficiency after colorectal or coloanal anastomosis is still the most frequent issue. Despite all minor local procedures, $9.5 \%$ to $27.5 \%$ of patients with anastomotic complications remain with a "temporary stoma" that is, in fact, permanent [10]. For such patients, major surgical revision such as reconstructing a new intestinal continuity (called "redo anastomosis) can be considered. However, redo surgery remains technically challenging, and unexpected intraoperative technical difficulties and high perioperative morbidity cause many surgeons to abandon these procedures in favor of leaving the defunctioning stoma in place.
Here, we reported for redo anastomosis surgery an overall success rate of $78.5 \%$ and a morbidity rate of $40.6 \%$ after a median follow-up of 43.4 months. These rates are in agreement with existing data that indicate success rates ranging from $43 \%$ to $100 \%$, with some variations depending on the different etiologies and techniques included. To date, the largest experience with PAF was reported in 2012 at Hôpital Saint-Antoine (Paris, France) [1], with 66 patients who were offered a redo coloanal anastomosis after a previous failed anastomosis. With a median follow-up of 33 months, absence of stoma was possible in 52 patients (78.8\%); 21 complications occurred immediately after surgery, with 10 of those patients (15.4\%) requiring surgical intervention. Notably, the observed functional outcomes and the quality of life of patients did not differ significantly from the results observed after primary anastomosis. In another case series published by Genser et al. [14], a total of 50 patients underwent redo surgery for failed colorectal or coloanal anastomosis. The results also confirmed that such a procedure was associated with a high success rate (88\%), acceptable morbidity, and reasonable long-term functional outcomes. Taken together, we believe that a redo procedure should be considered in selected patients with failed anastomosis for whom all conservative managements have failed.

Several risk factors associated with PAF that would leave a permanent stoma in patients have been reported $[10,15,16]$. In our multivariate analyses, lower tumor height increased the risk for PAF and subsequent redo surgery. We used the distance between the tumor and the anal verge because in a retrospective study, it can be measured more objectively than the height of the anastomosis. In 16 of the 32 patients who underwent redo surgery (50\%) in this study, the tumor was within $5 \mathrm{~cm}$ from the anal verge. This finding is consistent with previous data, although previous authors did not specifically focus on PAF [17-21]. In a previous multicenter study by Park et al. [22], compared with a control group, male patients with a tumor located within $7 \mathrm{~cm}$ from the anal verge had a relative risk of 2.6 of developing anastomotic complications. Rullier et al. [23] also reported that the anastomotic leakage rate for anastomosis locations within $5 \mathrm{~cm}$ was 6.5 times greater than it was for locations $5 \mathrm{~cm}$ or father from the anal verge. Thus, patients with low rectal lesions should be informed preoperatively of the possibility of PAF, and a way to reduce the impact of leakage should be aggressively considered.

Minimal invasive surgery has been gaining acceptance as a valid method for the management of patients with colorectal disease. However, a laparoscopic revision for PAF is rarely performed, so a limited number of experiences have been published on this subject. Laparoscopic surgery has several advantages over open surgery, such as magnified views, reduced minor oozing due to a pneumoperitoneum, and meticulous dissection in a confined pelvic space. In addition, increased laparoscopic experiences and advances in endoscopic instruments (i.e., advanced vessel sealing devices) have rendered complex laparoscopic procedures possible. The present study demonstrated that compared to the open redo 
surgery group, the laparoscopic redo surgery group had a relatively shorter hospital stay, significantly fewer wound-related morbidities, and a comparable success rate.

The primary limitation of the study is the inherent selection bias and patient confounders associated with a single-center retrospective study. The indications for redo surgery were heterogeneous, and the sample size was only 32 cases. Our findings may not be generalizable to other settings because the present data were based on the experiences of a specialized institution. Only four experienced surgical teams performed all procedures. Lack of functional outcome data is another limitation of this study. If a redo anastomosis is technically feasible and safe, the next question that needs to be answered concerns the functional outcome after revision of a coloanal or a colorectal anastomosis. In the present study, no patient requested a colostomy because of poor anal function after redo surgery. However, the objective data on continence disturbances, such the data that can be obtained from answers on a standardized gastrointestinal functional questionnaire, were incomplete; hence, these could not be assessed in this study. The current focus of our research includes the prospective evaluation of the quality of life, bowel function, and long-term genitourinary function of patients after a redo anastomosis.

In conclusion, a redo anastomosis for the treatment of patients with a PAF is a valuable surgical option that allows stoma reversal in nearly $80 \%$ of patients. Lower tumor height $(<5 \mathrm{~cm}$ from anal verge) is an independent risk factor for a PAF and subsequent redo surgery. Laparoscopic redo surgery seems to be a safe and feasible alternative to conventional surgery in terms of short-term outcomes. To confirm the authors' initial experience in redo surgery for treating patients with a PAF, multi-institutional studies with large-scale data are warranted.

\section{CONFLICT OF INTEREST}

No potential conflict of interest relevant to this article was reported.

\section{REFERENCES}

1. Pitel S, Lefèvre JH, Tiret E, Chafai N, Parc Y. Redo coloanal anastomosis: a retrospective study of 66 patients. Ann Surg 2012; 256:806-10.

2. Luchtefeld MA, Milsom JW, Senagore A, Surrell JA, Mazier WP. Colorectal anastomotic stenosis. Results of a survey of the ASCRS membership. Dis Colon Rectum 1989;32:733-6.

3. Schlegel RD, Dehni N, Parc R, Caplin S, Tiret E. Results of reoperations in colorectal anastomotic strictures. Dis Colon Rectum 2001;44:1464-8.

4. Sloothaak DA, Buskens CJ, Bemelman WA, Tanis PJ. Treatment of chronic presacral sinus after low anterior resection. Colorectal Dis 2013;15:727-32.

5. Musters GD, Borstlap WA, Bemelman WA, Buskens CJ, Tanis PJ.
Intersphincteric completion proctectomy with omentoplasty for chronic presacral sinus after low anterior resection for rectal cancer. Colorectal Dis 2016;18:147-54.

6. Watanabe J, Ota M, Kawaguchi D, Shima H, Kaida S, Osada S, et al. Incidence and risk factors for rectovaginal fistula after low anterior resection for rectal cancer. Int J Colorectal Dis 2015;30: 1659-66.

7. Nakagoe T, Sawai T, Tuji T, Nanashima A, Yamaguchi H, Yasutake T, et al. Successful transvaginal repair of a rectovaginal fistula developing after double-stapled anastomosis in low anterior resection: report of four cases. Surg Today 1999;29:443-5.

8. Elkins TE, DeLancey JO, McGuire EJ. The use of modified Martius graft as an adjunctive technique in vesicovaginal and rectovaginal fistula repair. Obstet Gynecol 1990;75:727-33.

9. Khanduja KS, Padmanabhan A, Kerner BA, Wise WE, Aguilar PS. Reconstruction of rectovaginal fistula with sphincter disruption by combining rectal mucosal advancement flap and anal sphincteroplasty. Dis Colon Rectum 1999;42:1432-7.

10. den Dulk M, Smit M, Peeters KC, Kranenbarg EM, Rutten HJ, Wiggers T, et al. A multivariate analysis of limiting factors for stoma reversal in patients with rectal cancer entered into the total mesorectal excision (TME) trial: a retrospective study. Lancet Oncol 2007;8:297-303.

11. Bailey CM, Wheeler JM, Birks M, Farouk R. The incidence and causes of permanent stoma after anterior resection. Colorectal Dis 2003;5:331-4.

12. Deloyers L. Technic permitting the easy assurance of continuity of the colon \& conservation of sphincter after excision of the left transverse hemicolon \& entire left colon; possible inclusion of rectum. J Chir (Paris) 1958;75:147-55.

13. Clavien PA, Barkun J, de Oliveira ML, Vauthey JN, Dindo D, Schulick RD, et al. The Clavien-Dindo classification of surgical complications: five-year experience. Ann Surg 2009;250:187-96.

14. Genser L, Manceau G, Karoui M, Breton S, Brevart C, Rousseau G, et al. Postoperative and long-term outcomes after redo surgery for failed colorectal or coloanal anastomosis: retrospective analysis of 50 patients and review of the literature. Dis Colon Rectum 2013;56:747-55.

15. Herrle F, Sandra-Petrescu F, Weiss C, Post S, Runkel N, Kienle P. Quality of life and timing of stoma closure in patients with rectal cancer undergoing low anterior resection with diverting stoma: a multicenter longitudinal observational study. Dis Colon Rectum 2016;59:281-90.

16. Floodeen H, Lindgren R, Matthiessen P. When are defunctioning stomas in rectal cancer surgery really reversed? Results from a population-based single center experience. Scand J Surg 2013;102: 246-50.

17. Law WL, Chu KW. Anterior resection for rectal cancer with mesorectal excision: a prospective evaluation of 622 patients. Ann Surg 2004;240:260-8.

18. Mäkelä JT, Kiviniemi H, Laitinen S. Risk factors for anastomotic leakage after left-sided colorectal resection with rectal anastomo- 
sis. Dis Colon Rectum 2003;46:653-60.

19. Karliczek A, Harlaar NJ, Zeebregts CJ, Wiggers T, Baas PC, van Dam GM. Surgeons lack predictive accuracy for anastomotic leakage in gastrointestinal surgery. Int J Colorectal Dis 2009;24:56976.

20. Kingham TP, Pachter HL. Colonic anastomotic leak: risk factors, diagnosis, and treatment. J Am Coll Surg 2009;208:269-78.

21. Warschkow R, Steffen T, Thierbach J, Bruckner T, Lange J, Tarantino I. Risk factors for anastomotic leakage after rectal cancer re- section and reconstruction with colorectostomy. A retrospective study with bootstrap analysis. Ann Surg Oncol 2011;18:2772-82.

22. Park JS, Choi GS, Kim SH, Kim HR, Kim NK, Lee KY, et al. Multicenter analysis of risk factors for anastomotic leakage after laparoscopic rectal cancer excision: the Korean laparoscopic colorectal surgery study group. Ann Surg 2013;257:665-71.

23. Rullier E, Laurent C, Garrelon JL, Michel P, Saric J, Parneix M. Risk factors for anastomotic leakage after resection of rectal cancer. Br J Surg 1998;85:355-8. 